OPEN ACCESS

Edited by:

Lam Dai Vu,

Vlaams Instituut voor

Biotechnologie, Belgium

Reviewed by:

Jing Zhang,

Nanjing Agricultural University, China

$\mathrm{TaO} \mathrm{Hu}$,

Chinese Academy of Sciences

(CAS), China

Xunzhong Zhang,

Virginia Tech, United States

*Correspondence:

Zhou Li

lizhou1986814@163.com

Yan Peng

pengyanlee@163.com

†These authors have contributed equally to this work

Specialty section:

This article was submitted to

Plant Physiology,

a section of the journal

Frontiers in Plant Science

Received: 31 July 2021 Accepted: 27 September 2021

Published: 28 October 2021

Citation:

Li Z, Tang M, Hassan MJ, Zhang Y, Han L and Peng Y (2021) Adaptability to High Temperature and Stay-Green Genotypes Associated With Variations in Antioxidant, Chlorophyll Metabolism, and $\gamma$-Aminobutyric Acid Accumulation in Creeping Bentgrass Species. Front. Plant Sci. 12:750728.

doi: 10.3389/fpls.2021.750728

\section{Adaptability to High Temperature and Stay-Green Genotypes Associated With Variations in Antioxidant, Chlorophyll Metabolism, and $\gamma$-Aminobutyric Acid Accumulation in Creeping Bentgrass Species}

\author{
Zhou Li ${ }^{1,2 * t}$, Mingyan Tang ${ }^{1 \dagger}$, Muhammad Jawad Hassan ${ }^{1}$, Yan Zhang ${ }^{1}$, Liebao Han ${ }^{2}$ and \\ Yan Peng ${ }^{1 *}$ \\ ${ }^{1}$ College of Grassland Science and Technology, Sichuan Agricultural University, Chengdu, China, ${ }^{2}$ Institute of Turfgrass \\ Science, Beijing Forestry University, Beijing, China
}

High temperature limits the cultivation and utilization of cool-season plants in many regions worldwide. Recently, extreme hot waves swept across the globe in summer, leading to enormous economic loss. The evaluation and identification of genotypic variation in thermotolerance within species are critical to breeding for environmental adaptation and also provide potential materials to explore thermo-resistant mechanism in plants. Forty-two accessions of creeping bentgrass (Agrostis stolonifera), which is a cool-season perennial grass for turf and ecological remediation, were collected from 15 different countries. Physiological traits, namely, chlorophyll (Chl) content, electrolyte leakage, photochemical efficiency, performance index on absorption basis, leaf relative water content, and osmotic potential were used to evaluate the heat tolerance of these materials in controlled growth chambers and field during summer. Stay-green and early-aging genotypes were selected to further reveal the potential mechanism of tolerance to senescence and heat damage associated with alterations in Chl metabolism, antioxidant and photosynthetic capacity, and endogenous $\gamma$-aminobutyric acid (GABA). Findings showed that there were significant genetic variations in physiological traits among 41 materials in response to high temperature stress. The 13M, PROVIDENCE, and LOFTS L-93 were the top three accessions with superior tolerance to heat and summer stress than other materials in terms of laboratory and field tests. In response to heat stress, the stay-green genotype PROVIDENCE exhibited significantly higher photochemical efficiency, net photosynthetic rate, transpiration rate, and water use efficiency than the heat-susceptible W6 6570. Delayed leaf senescence in relation to less Chl loss was detected in the PROVIDENCE associated with maintenance of significantly higher expression levels of Chl-anabolic genes (AsCHLH, AsPBGD, and AsPOR) and lower Chl-catabolic gene 
AsPPH under heat stress. Genetic attributes, such as better capacity to scavenge reactive oxygen species and higher endogenous GABA content could play positive roles in alleviating heat-induced senescence, oxidative damage, and metabolic disturbance in the PROVIDENCE.

Keywords: resource evaluation, thermotolerance, oxidative damage, senescence (leaf), metabolism, environmental stress

\section{INTRODUCTION}

Plants often suffer from various environmental stresses in nature; even cultivated crops under intensive care are easily affected by adverse environmental conditions. Extreme high temperature occurs frequently across the whole world and poses a major challenge to the cultivation and utilization of most crops in temperate regions (Sun et al., 2019). Because of the predicted rise in global temperature, heat stress-induced loss in crop economy will further expand worldwide (Van Vuuren et al., 2009). The identification of genetic variation in thermotolerance in one particular plant species is an essential requirement for the breeding and cultivation of a new variety. Previous studies have shown that wheat (Triticum aestivum) genotypes exhibited a significant variation in heat tolerance, and that these diverse genotypes could be used in wheat breeding programs for heat tolerance (Ahamed et al., 2010; Thistlethwaite et al., 2015; Sharma et al., 2016). As the third most abundant flowering plants, grass species exhibit extensive adaptation to abiotic stress and variations in stress tolerance, such as thermotolerance (Huang et al., 2014). The study of Sun et al. (2014) demonstrated that a higher genotypic variation in heat tolerance was found in gramineous tall fescue (Festuca arundinacea) species through evaluating 120 accessions from America, European, Africa, and Asia. Creeping bentgrass (Agrostis stolonifera), a perennial herb with genetic diversity, is widely distributed worldwide and used for lawn and forage. However, creeping bentgrass is a cool-season grass mainly adapting to cool-humid climate (Huang and Gao, 2000). The evaluation and identification of genotypic variation in thermotolerance within the species is critical to the breeding for stress tolerance and also provide potential materials to explore thermo-resistant mechanism in perennial plant species.

The stay-green genotype is regarded as an important trait for horticultural crops such as turfgrass. Heat stress accelerates leaf senescence associated with chlorophyll (Chl) degradation and loss (Jespersen et al., 2016). It has been reported that alterations in gene expression or enzyme activities responsible for $\mathrm{Chl}$ synthesis or degradation affected heat-induced senescence in different plants species. For example, the downregulation of Chl catabolic genes, such as $L p P P H$ encoding pheophytin pheophorbide hydrolyase by exogenous chemicals calcium dichloride, salicylic acid, and urea significantly alleviated heatinduced leaf senescence of perennial ryegrass (Lolium perenne) (Jing et al., 2019). Persistent heat stress accelerated leaf chlorosis of white clover (Trifolium repens) positively related to increases in transcript levels of chlorophyllase (CHLASE) and pheophorbide a oxygenase (PAO) genes for Chl degradation (Luo et al., 2020). The inhibition of Chl biosynthesis, as reflected by significant declines in activities of Chl-anabolic enzymes such as porphobilinogen deaminase (PBGD), magnesium-chelatase $(\mathrm{Mg}-\mathrm{CHT})$, and protochlorophyllide reductase (POR), was correlated with a significant increase in heat-induced leaf senescence of cucumber (Cucumis sativus) (Tewari, 1998). In bentgrass species, thermal rough bentgrass (Agrostis scabra) exhibited a significant delay in leaf senescence associated with lower Chl-degrading enzyme chlorophyllase (CHLASE) activity when compared with creeping bentgrass, but there was no significant difference in PBGD activity after 42 days of heat stress (Rossi et al., 2017). The maintenance of higher Chl content in leaves is propitious to growth and mitigation of photoinhibition for most of crops during hot summer, since $\mathrm{Chl}$ is the most important pigment for light absorption and conversion (Chen, 2014). Chl degradation induced by heat stress slows down photosynthetic process, leading to growth retardation and yield loss (Lipiec et al., 2013). Higher Chl content was found to be the key indicator of better heat and drought tolerance in wheat genotypes (Rehman et al., 2016). In addition, the overaccumulation of reactive oxygen species (ROS) causes oxidative damage to chloroplast, mitochondria, and other organelles, contributing to early aging and cell death under adverse environmental conditions, such as a long period of high temperature in nature (Parent et al., 2008). The study of Jing et al. (2019) demonstrated that excessive ROS accumulation resulted in oxidative damage to $\mathrm{Chl}$ under heat stress, which aggravated leaf senescence.

Transitional and warm climatic regions limit the intensive cultivation of cool-season plants and increase the maintenance and management cost of many horticultural crops during summer (Malhotra, 2017). Some earlier studies have evaluated differences in heat tolerance of creeping bentgrass, but were restricted to less cultivars or materials. In this study, 42 creeping bentgrass accessions were collected from 15 different countries. Physiological traits, namely, Chl content, electrolyte leakage (EL), photochemical efficiency (Fv/Fm), performance index on absorption basis $\left(\mathrm{PI}_{\mathrm{ABS}}\right)$, leaf relative water content (RWC), and osmotic potential (OP) were used for evaluating the heat tolerance of these materials in controlled greenhouse and field during summer. Stay-green and early-aging genotypes were selected to further reveal the potential mechanism of heat tolerance associated with alterations in Chl metabolism, antioxidant and photosynthetic capacity, and content of endogenous $\gamma$-aminobutyric acid (GABA), a crucial metabolite involved in $\mathrm{Chl}$ metabolism and heat tolerance in plants (Li et al., 2016, 2021). Comparing and identifying these genotypes differing in heat tolerance under field conditions during summer and in controlled greenhouses will provide more 
accurate information for the breeding and utilization of creeping bentgrass species.

\section{MATERIALS AND METHODS}

\section{Plant Materials and Treatments}

Forty-two creeping bentgrass materials were collected from National Plant Germplasm System (NPGS) in the United States and Beijing Zhengdao Ecology Science and Technology Ltd. These materials are distributed in or have originated from 15 different countries (Supplementary Table 1). In March 2019, 30 seeds of each material were sown in a cylindrical plastic container (11 cm in diameter and $33 \mathrm{~cm}$ in length) containing sand and soil $(1: 1, \mathrm{w}: \mathrm{w})$. All the materials were placed in a greenhouse [average $24 / 17^{\circ} \mathrm{C}$ (day/night), $65 \%$ relative humidity, and 700 $\mu \mathrm{mol} \cdot \mathrm{m}^{-2} \cdot \mathrm{s}^{-1}$ photosynthetically active radiation (PAR)]. After 7 days of germination, seedlings were watered using half-strength Hoagland's solution (Hoagland and Arnon, 1950) once a week and trimmed twice or thrice a week to maintain a canopy height of about $3 \mathrm{~cm}$. All the materials were cultivated in the greenhouse for 2 months until grasses had covered the whole mouth of the pipe. Grasses were moved into a walking chamber for 7 days of acclimation $\left[23 / 18^{\circ} \mathrm{C}\right.$ (day/night), $65 \%$ relative humidity, and $\left.700 \mu \mathrm{mol} \cdot \mathrm{m}^{-2} \cdot \mathrm{s}^{-1} \mathrm{PAR}\right]$. The plants were then divided into two groups: one group was placed in a normal walking chamber (the same as above), and the other was placed in a walking chamber with high temperature $\left[37 / 30^{\circ} \mathrm{C}\right.$ (day/night), 65\% relative humidity, and $700 \mu \mathrm{mol} \cdot \mathrm{m}^{-2} \cdot \mathrm{s}^{-1}$ PAR]. All the materials were completely arranged in walking chambers, and each material included four biological replicates (four containers). Leaf samples were taken after 30 days of normal cultivation and heat stress.

For the evaluation of heat tolerance of 18 materials in the field, the sod of each material $(5 \mathrm{~cm}$ in diameter) was planted in the Research Farm of Sichuan Agricultural University (Chongzhou, Sichuan, China, east longitude $103^{\circ} 07^{\prime}-103^{\circ} 49^{\prime}$ and north latitude $30^{\circ} 30^{\prime}-30^{\circ} 53^{\prime}$ ) in September 2019. All the materials were watered by half-strength Hoagland's solution once a week and trimmed twice a week to maintain a canopy height of about $3-5 \mathrm{~cm}$ until each material formed a circular turf with $40 \mathrm{~cm}$ in diameter. For physiochemical properties, soil pH, total nitrogen, available phosphate, available potassium, and organic matter was $6.3,2.03 \mathrm{~g} / \mathrm{kg}, 10.2 \mathrm{mg} / \mathrm{kg}, 101.1 \mathrm{mg} / \mathrm{kg}$, and 37.6 $\mathrm{g} / \mathrm{kg}$, respectively. All the materials were completely arranged in the field, and each included four biological replicates. The identification of heat tolerance was conducted in the summer of 2020. From June 1 to July 31 , the total number of daily maximum temperature over $30^{\circ} \mathrm{C}$ amounted to 32 days, and the maximum temperature was $37.3^{\circ} \mathrm{C}$ on July 26 (Supplementary Figure 1). Volumetric soil water content was maintained at a $70-80 \%$ field capacity to avoid drought. The leaf samples were collected on June 1 , June 28 , and July 31,2020 . The 18 materials with better heat tolerance were selected based on the first experiment that was conducted in the walking chambers.

For the comparative analysis of heat tolerance between heat-sensitive (W6 6570) and heat-tolerant (PROVIDENCE) materials, the sod of each material $(5 \mathrm{~cm}$ in diameter) was planted in a cylindrical plastic container $(11 \mathrm{~cm}$ in diameter and $33 \mathrm{~cm}$ in length) for 2 months in the greenhouse (cultivation condition and maintenance measure were the same as those mentioned above). After being acclimated in growth chambers for 7 days, the grasses were divided into two groups: one group was placed in a normal growth chamber $\left[23 / 18^{\circ} \mathrm{C}\right.$ (day/night), $65 \%$ relative humidity, and $\left.700 \mu \mathrm{mol} \cdot \mathrm{m}^{-2} \cdot \mathrm{s}^{-1} \mathrm{PAR}\right]$, and the other group was placed in a growth chamber with high temperature $\left[38 / 33^{\circ} \mathrm{C}\right.$ (day/night), 65\% relative humidity, and $\left.700 \mu \mathrm{mol} \cdot \mathrm{m}^{-2} \cdot \mathrm{s}^{-1} \mathrm{PAR}\right]$ for 15 days. All the materials were completely arranged in the growth chambers, and each included four biological replicates (four containers). The leaf samples were taken at 0 and $3 \mathrm{~h}$, and 3,10 , and 15 days of normal cultivation and heat stress. The selection of the two materials was based on the comprehensive evaluation of the first experiment in the walking chambers and the second experiment in the field.

\section{Measurements of Turf Quality, Water Status, and Photosynthetic Parameters}

The evaluation of turf quality (TQ) was based on color, density, and uniformity of turf with nine scores for fully turgid and green turf, six scores for minimal acceptable level, and one score for completely dry and yellow turf (Beard and Batten, 2001). For leaf RWC, fresh leaves were mown from plants and weighed to get the fresh weight (FW), and these leaves were then soaked in deionized water for $12 \mathrm{~h}$. After being taken out and blotted dry, the turgid weight (TW) of the leaves was recorded. The leaves were dried at $105^{\circ} \mathrm{C}$ for $20 \mathrm{~min}$ and later at $80^{\circ} \mathrm{C}$ until the dry weight (DW) became constant. The RWC was calculated based on the formula RWC $(\%)=[(\mathrm{FW}-\mathrm{DW}) /(\mathrm{TW}-\mathrm{DW})]$ $\times 100 \%$ (Barrs and Weatherley, 1962). For the determination of $\mathrm{OP}$, the fresh leaves were hydrated in deionized water for $12 \mathrm{~h}$ and the fully turgid leaves were frozen in liquid nitrogen for $10 \mathrm{~min}$. When the frozen leaves were thawed in ice bath, the sap in the leaves was pressed and then inserted $(10 \mu \mathrm{l})$ into an osmometer (Wescor, Inc., Logan, UT, United States) to get osmolality $\left(\mathrm{mmol} \mathrm{kg}^{-1}\right)$ and the $\mathrm{OP}=-([$ osmolality $] \times[0.001]$ $\times$ [2.58]) (Blum, 1989). Chl content was determined according to the method of Amnon (1949). Fv/Fm and $\mathrm{PI}_{\mathrm{ABS}}$ were detected by a Chl fluorescence system (Pocket PEA) before the leaves were clipped with leaf clips for 20-min dark adaptation. A portable photosynthesis system (CIRAS-3; PP Systems, United States) was used for detecting net photosynthesis rate $(\mathrm{Pn})$, transpiration rate ( $\mathrm{Tr}$ ), and water use efficiency (WUE). The leaf chamber (400 $\mu \mathrm{L} \mathrm{L}^{-1} \mathrm{CO}_{2}$ and $800 \mu \mathrm{mol}$ photon $\mathrm{m}^{-2}$ red and blue light) was overspread with a single layer of leaves, and readings were recorded after the readings became stable.

\section{Measurements of Oxidative Damage, Antioxidant Capacity, and Cell Membrane Stability}

For the determination of superoxide anion $\left(\mathrm{O}_{2}^{-}\right)$radical content, $0.1 \mathrm{~g}$ of leaves were homogenated with $1.5 \mathrm{ml}$ of $65 \mathrm{mM}$ phosphate buffered saline (PBS, $\mathrm{pH} 7.8$ ), and the mixture was centrifuged at $10,000 \mathrm{~g}$ for $30 \mathrm{~min}$ at $4^{\circ} \mathrm{C}$. The supernatant, $0.5 \mathrm{ml}$, was mixed with $0.5 \mathrm{ml}$ of PBS and. $1 \mathrm{ml}$ of $10 \mathrm{mM}$ hydrochloride, and then incubated at $25^{\circ} \mathrm{C}$ for $20 \mathrm{~min}$. Sulfanilamide $0.5 \mathrm{ml}$ and $58 \mathrm{mM}$ and $0.5 \mathrm{ml}$ of $7 \mathrm{mM}$ a-naphthylamine were added into the 
mixture and then incubated at $25^{\circ} \mathrm{C}$ for $20 \mathrm{~min}$. Chloroform $2 \mathrm{ml}$ was added and shaken up. The absorbance of the chloroform was measured at $530 \mathrm{~nm}$ (Elstner and Heupel, 1976). The hydrogen peroxide $\left(\mathrm{H}_{2} \mathrm{O}_{2}\right)$ content was detected using the method of Velikova et al. (2000). For the evaluation of malondialdehyde (MDA) content, the method of Dhindsa et al. (1981) was used. An assay kit (ABTS-1-D; Suzhou Comin Biotechnology Co., Ltd., China) was used for determining total antioxidant capacity (TAC) according to the instructions of the manufacturer, and $0.1 \mathrm{~g}$ of fresh leaves were used. For the determination of EL, $0.1 \mathrm{~g}$ of the fresh leaves were immersed in $35 \mathrm{ml}$ deionized water at $24^{\circ} \mathrm{C}$ for $24 \mathrm{~h}$, and the conductance of leaching liquor was detected using a conductivity meter (YSI Model 32; Yellow Springs Instrument Co., United States) as the initial conductivity $\left(\mathrm{C}_{1}\right)$. The leaves and a solution were heated at $100^{\circ} \mathrm{C}$ for $30 \mathrm{~min}$, and the conductance of the solution was detected as the final conductivity $\left(\mathrm{C}_{2}\right)$. EL was then calculated based on the formula $\mathrm{EL}(\%)=\mathrm{C}_{1} / \mathrm{C}_{2} \times 100 \%$ (Blum and Ebercon, 1981).

\section{Measurements of Endogenous GABA Content}

Endogenous GABA content was detected by enzyme-linked immunosorbent assay (ELISA), and the assay kit (ml-E3042) was purchased from Shanghai Enzyme-linked Biotechnology Co. (Shanghai, China). Briefly, $0.1 \mathrm{~g}$ of the fresh leaves were ground with $2 \mathrm{ml}$ of PBS ( $\mathrm{pH} 7.4)$, and the mixture was centrifuged at $3,000 \mathrm{~g}$ for $20 \mathrm{~min}$. The supernatant was used for the determination of the GABA content according to the instructions of the manufacturer.

\section{Gene Expression Analysis}

Gene expression levels were determined by real-time quantitative polymerase chain reaction (qRT-PCR). The total RNA in the leaves was extracted using RNeasy Mini Kit (Qiagen, Germany) and according to the instructions of the manufacturer. These RNAs were reverse-transcribed to cDNA using the Revert Aid First Stand cDNA Synthesis Kit (Fermentas, Lithuania). For the determination of gene expression levels, an iCycleriQ (Bio-Rad, United States) qRT-PCR detection system with SYBR Green Supermix (Bio-Rad) was used. The conditions of the PCR protocol for all the genes, namely, As $\beta$-actin (internal reference gene), Chl-metabolism-related genes (AsPBGD, AsCHLH-encoding magnesium-chelatase $\mathrm{H}$ subunit, $A s P P H$, and $A s P O R), A s G A D 1$-encoding glutamate decarboxylase involved in GABA biosynthesis, and senescenceassociated genes (As120, Ash12, AsSAG12, and AsSAG39) were as follows: $5 \mathrm{~min}$ at $95 \mathrm{C}$ and 40 repeats of denaturation at $95^{\circ} \mathrm{C}$ for $15 \mathrm{~s}$, annealing at $55-60^{\circ} \mathrm{C}$ (Supplementary Table 2) for $45 \mathrm{~s}$, followed by heating the amplicon from 60 to $95^{\circ} \mathrm{C}$ to obtain the melting curve. Primer sequences of all the genes are shown in Supplementary Table 2. Transcript levels of all the genes were calculated based on the formula $2^{-\Delta \Delta \mathrm{Ct}}$ described by Kenneth and Thomas (2002).

\section{Statistical Analysis}

Significant differences among treatments were tested by Fisher's protected least significance (LSD) test at a 0.05 probability level, and Pearson correlation analysis was performed at a 0.05 and 0.01 probability level (SAS 9.1; SAS Institute, Cary, NC, United States). Subordinate function values analysis (SFVA) was performed for a comprehensive evaluation of heat tolerance based on different physiological parameters. If a parameter had a positive relationship with heat tolerance, the formula $U_{i j}=$ $\left(\mathrm{X}_{\mathrm{ij}}-\mathrm{X}_{\mathrm{jmin}}\right) /\left(\mathrm{X}_{\mathrm{jmax}}-\mathrm{X}_{\mathrm{jmin}}\right)$ was used. If a parameter had a negative relationship with heat tolerance, the formula $U_{i j}=1-\left(X_{i j}-\right.$ $\left.\mathrm{X}_{\mathrm{jmin}}\right) /\left(\mathrm{X}_{\mathrm{jmax}}-\mathrm{X}_{\mathrm{jmin}}\right)$ was used. $\mathrm{X}_{\mathrm{ij}}$ indicated the difference of mean value of the parameter $j$ between normal condition and heat stress in material $\mathrm{i} . \mathrm{X}_{\mathrm{jmin}}$ indicated the mimimum difference of mean value of the parameter $\mathrm{j}$ between normal condition and heat stress in material $\mathrm{i}$. $\mathrm{X}_{\mathrm{jmax}}$ indicated the maximum difference of mean value of the parameter $\mathrm{j}$ between normal conditions and heat stress in material $i$. The comprehensive evaluation index of heat tolerance was calculated based on the formula $\mathrm{B}=$ $\sum \mathrm{U}_{\mathrm{ij}} / \mathrm{n}$. $\mathrm{U}_{\mathrm{ij}}$ indicated the comprehensive score of the parameter $j$ in material i. $n$ indicated the total number of physiological parameters used for evaluating heat tolerance. The larger SFVA value, the better the heat tolerance. Hierarchical clustering (heat map) of physiological parameters was performed using the $\mathrm{R}$ statistical software (R3.5.2 by R Development Core Team).

\section{RESULTS}

\section{Evaluation of Heat Tolerance Among the 41 Materials in the Controlled Greenhouse}

There was an obvious difference among 41 materials in leaf RWC, OP, EL, Chl content, and $\mathrm{PI}_{\mathrm{ABS}}$ between control and heat stress (Supplementary Figures 1,2). The range of variation in difference in leaf RWC was from 4.2 to $44.3 \%$ (Supplementary Figure 1A). Maximum difference in RWC was observed in W6 6570 (44.3\%), followed by SEASIDE 2 (28.9\%) and W6 6569 (27.1\%). KLONOBAJA (4.2\%) and SMALL LIZARD (4.2\%) exhibited a minimum variation in RWC (Supplementary Figure 1A). For the change in OP, the variation ranged from 0.01 to $0.72 \mathrm{MPa}$ (Supplementary Figure 1B). The variation in OP of three materials (O93, W6 6574, and F-251) was less than $0.1 \mathrm{MPa}$; however, SR 1020 showed highest difference in OP (0.72 MPa) (Supplementary Figure 1B). A 1.11-62.41\% variation range was detected in EL among 41 materials. Minimum variation was found in PENN WAY (1.1\%) and the second to last was PA1 (1.9\%), whereas top three variations were found in the PENNEAGLE (46.4\%), PENNCROSS (46.0\%), and EMERALD (45.2\%), respectively (Supplementary Figure 2A). Heat stress caused a significant decline in Chl content of all the materials, and decreasing range was between 0.70 and $8.01 \mathrm{mg}$ $\mathrm{g}^{-1}$ (Supplementary Figure 2B). W6 6569 showed a maximum decline in Chl content, whereas TALEH $\left(0.7 \mathrm{mg} \mathrm{g}^{-1}\right)$ showed a minimum decrease in Chl content, followed by W6 6569 (1.1 mg $\mathrm{g}^{-1}$ ) and LOFTS L-93 (1.7 $\mathrm{mg} \mathrm{g}^{-1}$ ) (Supplementary Figure 2B). The most significant decline in $\mathrm{PI}_{\mathrm{ABS}}$ was observed in PENNEAGLE, and minimum values were found in NATIONAL and MSCB-11 (Supplementary Figure 2C).

Hierarchical clustering of five physiological parameters (EL, Chl, $\mathrm{PI}_{\mathrm{ABS}}$, RWC, and OP) among the 41 materials were mainly 

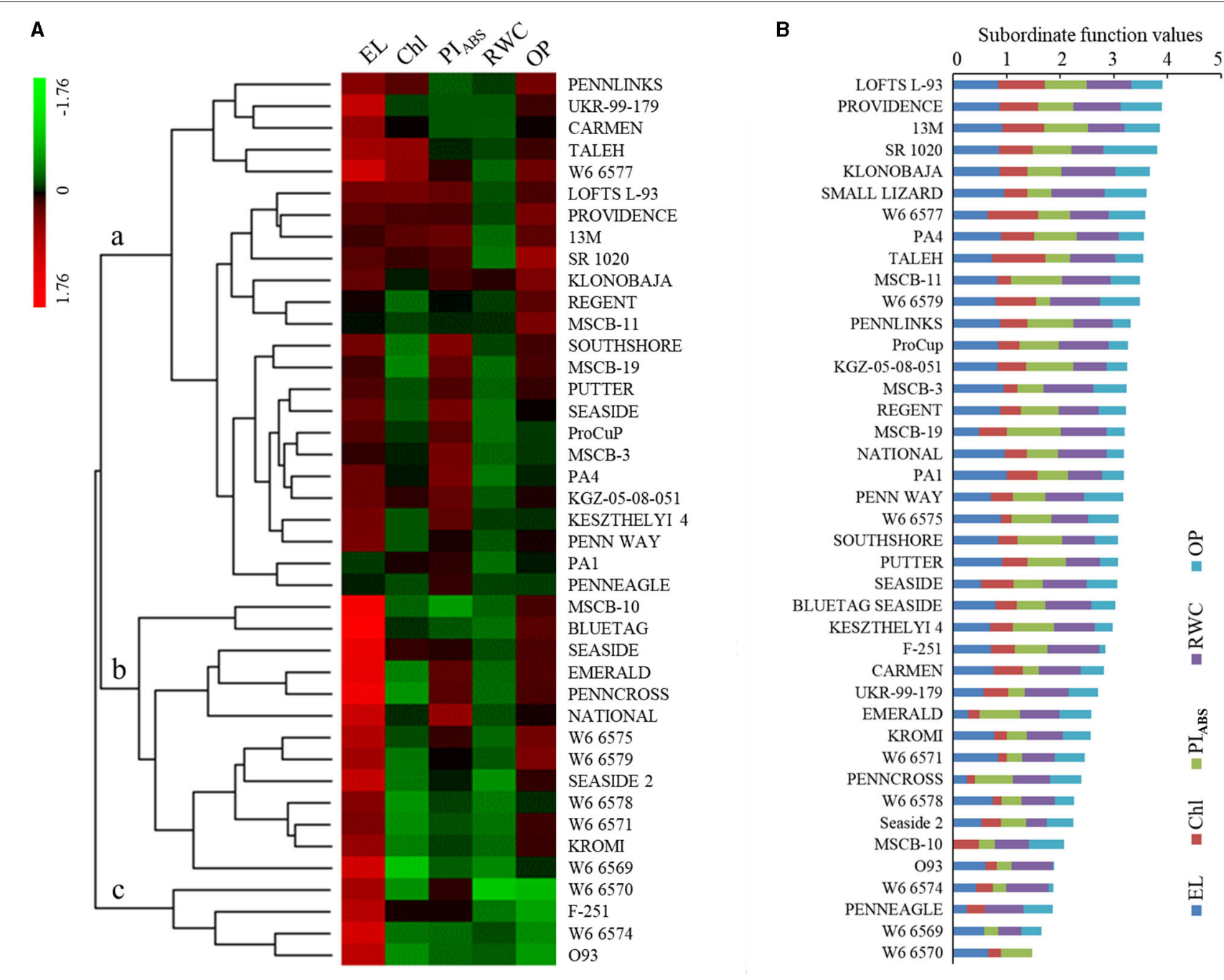

FIGURE 1 | Changes in (A) heat map that was made by $\log _{2} \mathrm{FC}$ (fold change of heat stress in relation to control under normal conditions) and (B) the subordinate function values analysis of five different physiological parameters for comprehensive evaluation of heat tolerance in 41 creeping bentgrass materials under heat stress in the controlled greenhouse.

divided into three subclusters ( $\mathrm{a}, \mathrm{b}$, and $\mathrm{c}$ ) in response to heat stress (Figure 1A). The parameters in the subcluster showed less changes under heat stress. EL, Chl, and RWC exhibited greater changes, but $\mathrm{PI}_{\mathrm{ABS}}$ and $\mathrm{OP}$ showed less changes in the subcluster b. Most parameters in the subcluster $c$ exhibited greater changes under heat stress (Figure 1A). Based on the SFVA, the heat tolerance of the 41 materials was ranked, and higher SFV means better heat tolerance (Figure 1B). LOFTS L-93 (top), PROVIDENCE (second), and 13M (third) had better heat tolerance than the other materials. PENNEAGLE, W6 6569, and W6 6570 exhibited less heat tolerance than the other 38 materials (Figure 1B). The Pearson correlation analysis found that the subordinate function value (SFV) was significantly correlated with EL, Chl, $\mathrm{PI}_{\mathrm{ABS}}$, RWC, or OP under heat stress (Table 1). The SFV and Chl had the highest correlation coefficient $(r=$ 0.681). EL, $\mathrm{PI}_{\mathrm{ABS}}$, RWC, and $\mathrm{OP}$ also showed high correlation coefficients with the SFV (Table 1).

\section{Evaluation of Heat Tolerance Among 18 Materials in the Field in Summer}

During summer, from June 1 to July 31, 2020, daily maximum average temperature ranged from 22.5 to $37.3^{\circ} \mathrm{C}$, and daily maximum average temperature above $30^{\circ} \mathrm{C}$ amounted to 32 days under field conditions (Figure 2A). In addition, there was a total of 11 days of daily maximum average temperature between 28 and $30^{\circ} \mathrm{C}$ (Figure 2A). High temperature stress in summer induced gradual decline in TQ of 18 materials with better tolerance selected from 41 materials based on the experiment conducted in the controlled greenhouse (Supplementary Figure 3A). On July 31, PROVIDENCE, 13M, PA4, and SMALL LIZARD showed higher TQ, but MSCB-19, KGZ-05-08-051, ProCup, and MSCB-3 showed lower TQ (Supplementary Figure 3A). On the contrary, a significant increase in EL was observed in all the materials (Figure 2C). SMALL LIZARD, PA4, 13M, 
TABLE 1 | Pearson correlation coefficient analysis based on six parameters, namely, mean subordinate function value (SFV), electrolyte leakage (EL), chlorophyll (Chl) content, performance index on absorption basis $\left(\mathrm{Pl}_{\mathrm{ABS}}\right)$, leaf relative water content (RWC), and osmotic potential (OP) among 41 creeping bentgrass accessions under heat stress.

\begin{tabular}{|c|c|c|c|c|c|c|}
\hline & SFV & EL & Chl & $\mathrm{PI}_{\mathrm{ABS}}$ & RWC & OP \\
\hline SFV & 1 & & & & & \\
\hline EL & $-0.575^{\text {“**” }}$ & 1 & & & & \\
\hline Chl & $0.681^{4 \star \star ”}$ & -0.151 & 1 & & & \\
\hline PIABS & $0.565^{\text {“**” }}$ & $-0.366^{\text {“*” }}$ & 0.185 & 1 & & \\
\hline RWC & $0.565^{\prime \star \star * ”}$ & -0.175 & $0.335^{\prime * \star ”}$ & 0.046 & 1 & \\
\hline OP & $0.583^{6 \star \star \star ”}$ & -0.028 & 0.326 “*” & 0.089 & $0.429 “ \star \star \star \prime$ & 1 \\
\hline
\end{tabular}

"*” or "**” indicates significance at $P<0.05$ or $P<0.01$, respectively.

PROVIDENCE exhibited lower EL than the other materials on June 28 and July 31 (Supplementary Figure 3B). Chl content, $\mathrm{Fv} / \mathrm{Fm}$, and $\mathrm{PI}_{\mathrm{ABS}}$ in the leaves decreased quickly during summer time (Supplementary Figures 4A-C). KLONOBAJA, TALEH, 13M, and SMALL LIZARD maintained higher $\mathrm{Chl}$ as compared with the remaining 14 materials (Supplementary Figure 4A). Decline in Fv/Fm was least in PROVEIDENCE and second lowest in LOFTS L-93 after summer (Supplementary Figure 4B). LOFTS L-93, KLONOBAJA, and $13 \mathrm{M}$ exhibited significantly higher $\mathrm{PI}_{\mathrm{ABS}}$ than the other materials in summer (Supplementary Figure 4C). Based on the SFVA of four parameters (TQ, EL, CHL, Fv/Fm, and $\mathrm{PI}_{\mathrm{ABS}}$ ), the heat tolerance of the 18 materials was ranked (Figure 2B). 13M exhibited strongest heat tolerance, followed by PROVIDENCE (second) and LOFTS L-93 (third). The heat tolerance of ProCup was worst. NATIONAL and MSCB-19 had the same score, and their heat tolerance was next to last among the 18 materials under field conditions in summer (Figure 2B). Figure 2C shows the phenotypic changes in the 18 materials during summer under field conditions. Based on comprehensive evaluations in the controlled greenhouse and under field conditions, $13 \mathrm{M}$, PROVIDENCE, and LOFTS L-93 were the top three materials with heat tolerance better than that of the other materials (Figures 1B, 2B).

\section{Differential Responses to Heat Stress in Photosynthesis and Chlorophyll Metabolism Between Heat-Tolerant and Heat-Sensitive Materials in Controlled Growth Chambers}

For the comparison experiment in controlled growth chambers, heat stress (15 days) made the leaves of heattolerant PROVIDENCE and heat-sensitive W6 6570 turn into yellow and also hindered their growth; however, heat stress had minor adverse effects on PROVIDENCE (Figure 3A). Chl content, Pn, Tr, and WUE in both PROVIDENCE and W6 6570 declined significantly under heat stress (Figures 3B-E). Obviously, PROVIDENCE exhibited higher Chl content, Pn, Tr, and WUE than W6 6570 under normal conditions and heat stress (Figures 3B-E). For the expression level of genes involved in Chl metabolism, the expression of $A s C H L H$ was significantly higher in W6 6570 than in PROVIDENCE at $3 \mathrm{~h}$, but was not different at 3 and $10 \mathrm{~d}$ under normal conditions (Figure 4A). Heat stress significantly decreased the expression of $A s C H L H$ in W6 6570, but increased its expression in PROVIDENCE at 3 days (Figure 4A). Under normal conditions, the expression of $A s P B G D$ gradually declined from $3 \mathrm{~h}$ to $10 \mathrm{~d}$ in W6 6570, but did not change in PROVIDENCE (Figure 4B). Under heat stress, PROVIDENCE exhibited a significantly higher AsPBGD expression than W6 6570 at $3 \mathrm{~h}$ (Figure 4B). The expression of AsPOR did not vary in PROVIDENCE, but gradually declined in W6 6570 under normal conditions (Figure 4C). PROVIDENCE had a significantly higher AsPOR expression than W6 6570 at 10 days under normal conditions and at 3 and 10 days under heat stress (Figure 4C). Heat stress significantly upregulated the expression of $A s P P H$ in the leaves of PROVIDENCE and W6 6570; however, the expression of $A s P P H$ was significantly lower in PROVIDENCE as compared with that in W6 6570 at $3 \mathrm{~h}$ and 3 days of heat stress (Figure 4D).

\section{Differential Responses to Heat Stress in Antioxidant Capacity, $\gamma$-Aminobutyric Acid, and Senescence-Associated Genes Expression Between Heat-Tolerant and Heat-Sensitive Materials in Controlled Growth Chambers}

There were no significant differences in $\mathrm{O}_{2}{ }^{-}, \mathrm{H}_{2} \mathrm{O}_{2}$, and MDA content between PROVIDENCE and W6 6570 under normal growth conditions, but heat stress significantly increased their accumulations in both materials (Figures 5A-C). W6 6570 exhibited a 41 or $45 \%$ increase in $\mathrm{O}_{2}{ }^{-}$- content compared with PROVIDENCE on the 10th or 15th day of heat stress, respectively (Figure 5A). Similarly, W6 6570 showed a significantly higher accumulation of $\mathrm{H}_{2} \mathrm{O}_{2}$ relative to PROVIDENCE on the 10th and 15 th day of heat stress (Figure $5 \mathbf{B}$ ). A 28 or $31 \%$ decrease in MDA content was found in PROVIDENCE as compared with that in W6 6570 on the 10th or 15th day of heat stress, respectively (Figure 5C). Heat stress induced a significant increase in TAC in PROVIDENCE and W6 6570, but the increase was more pronounced in PROVIDENCE. However, no significant difference in TAC existed between the two materials under normal conditions (Figure 5D). Endogenous GABA content and AsGADlexpression showed the same trend between PROVIDENCE and W6 6570 in response to heat stress, and significantly higher GABA content and AsGAD1expression were observed in PROVIDENCE than in W6 6570 under normal and heat conditions (Figures 6A,B). The expression of AsSAG12 was significantly upregulated by heat stress, but PROVIDENCE had a significantly lower expression level of AsSAG12 than W6 6570 under normal and heat conditions (Figure 7A). Expression levels of AsSAG39, Asl20, and Ash36 were not different between PROVIDENCE and W6 6570 under normal conditions and upregulated by heat stress (Figures 7B,C). W6 6570 showed a 106,54 , or $211 \%$ increase in the expression level of AsSAG39, Asl20, or Ash 36 compared with PROVIDENCE under heat stress, respectively (Figures 7B-D). 


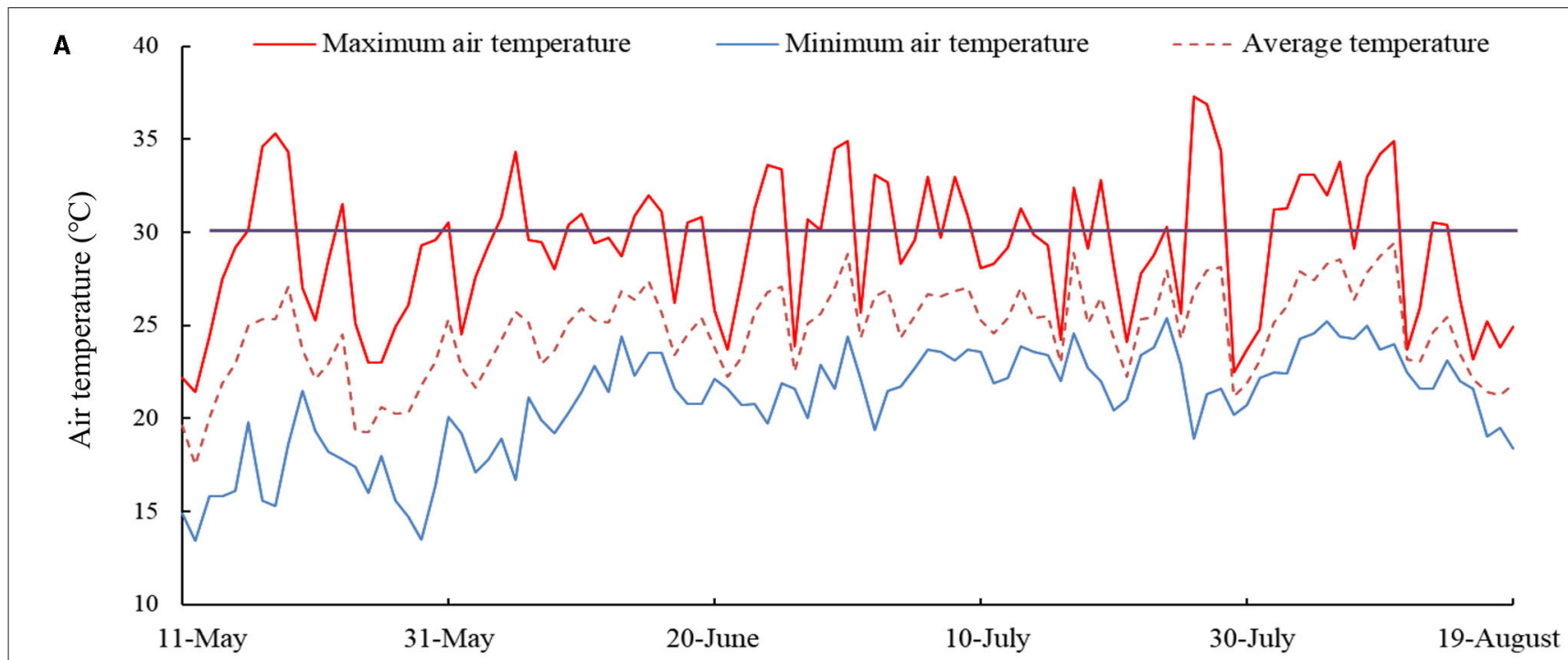

Changes in Air temperature in Chongzhou, China, May-August $2020(\mathrm{~m} / \mathrm{d})$

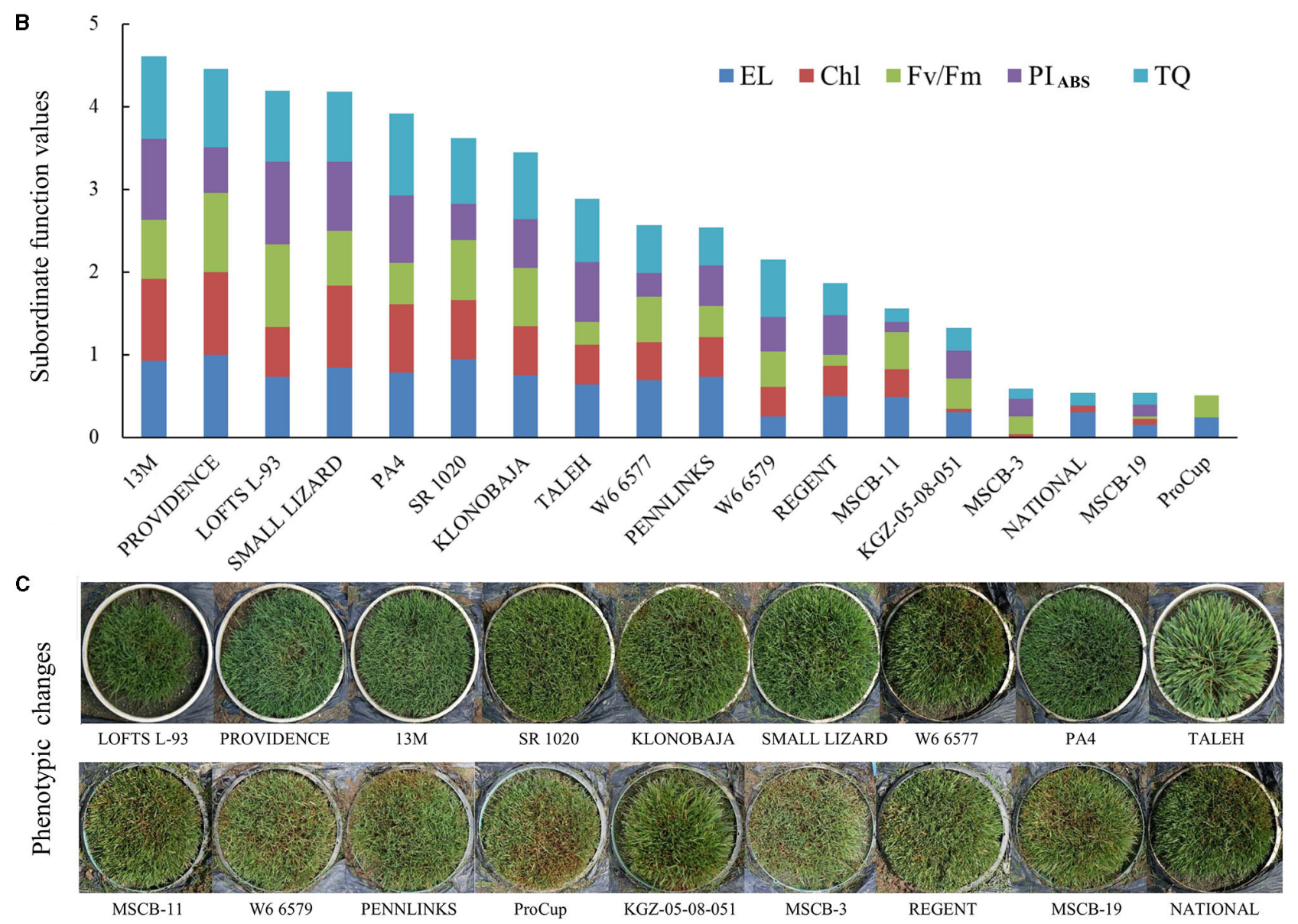

FIGURE 2 | Changes in (A) daily maximum, minimum, and average air temperature, (B) the subordinate function values analysis of five different physiological parameters for comprehensive evaluation of heat tolerance, and (C) phenotypes of 18 creeping bentgrass materials during summer in 2020 under field conditions. 


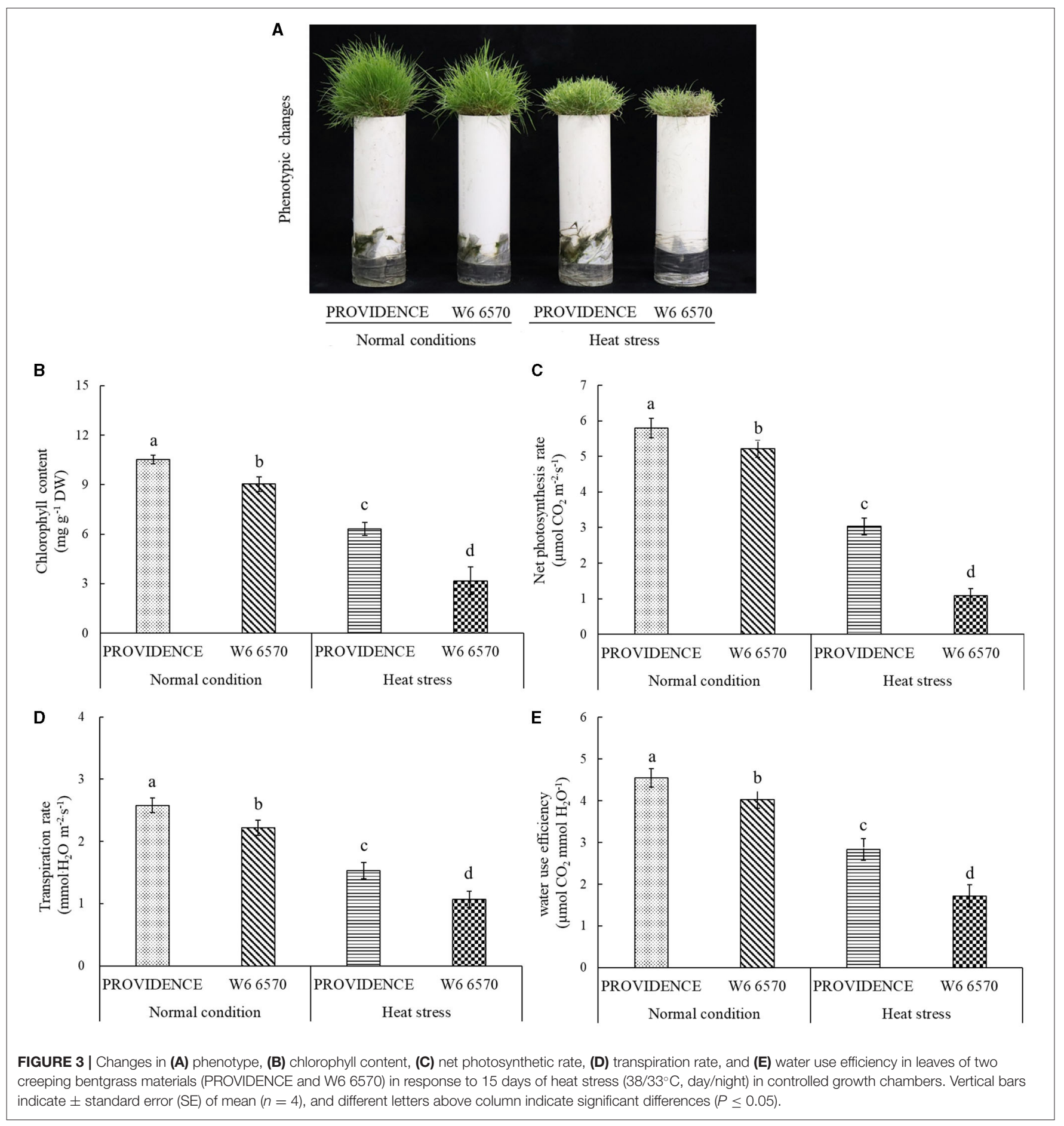

\section{DISCUSSION}

Cool-season plant species are highly vulnerable to consistent high temperature stress. However, most cool-season grasses, such as perennial ryegrass, Kentucky bluegrass (Poa pratensis), and tall fescue, exhibit significant variations in tolerance to heat stress because of the genetic diversity of the population (Minner et al., 1983; Imada et al., 1993; Sun et al., 2014).
Rapid and effective screening for heat-tolerant germplasms is of great value for breeding programs and also provides a guide for cultivation in warm regions. Cell membrane stability, as demonstrated by change in EL level, and Chl content have been widely used as critical and effective parameters to evaluate the variation in thermotolerance in different plant species (Sun et al., 2014; Rehman et al., 2016; Sharma et al., 2016). PI $\mathrm{ABS}_{\mathrm{A}}$ is considered a major indicator of leaf health status, because 


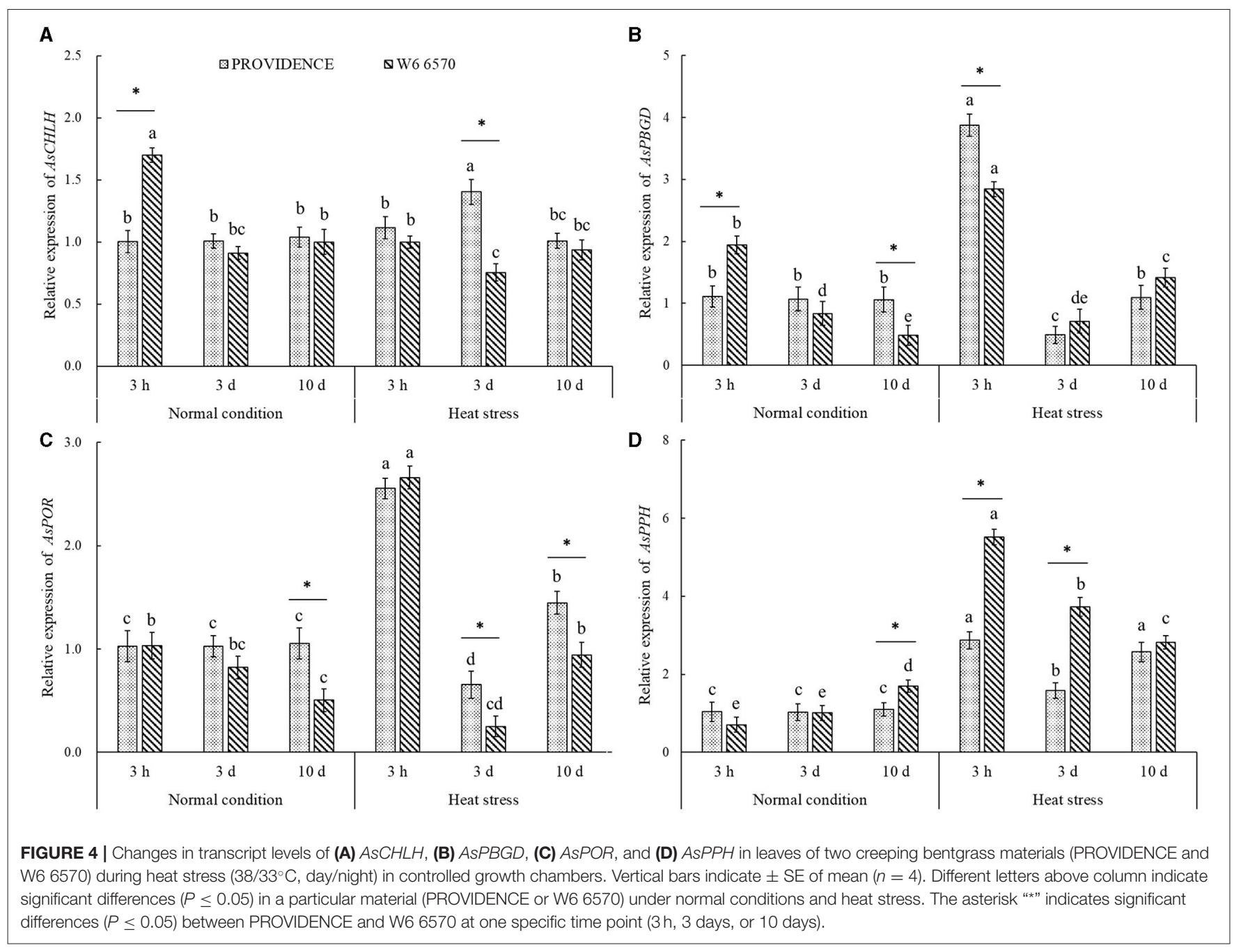

it synthetically reflects maximum photochemical efficiency and the number of activated photochemical reaction centers of photosystem II (PSII) in plant cells (Dai et al., 2019). In response to heat stress, the heat-tolerant maize (Zea mays) genotype "DKC7221" has the ability to maintain significantly higher PI $\mathrm{I}_{\mathrm{ABS}}$ than the heat-susceptible "P3167" (Doru, 2021). RWC and $\mathrm{OP}$ are the main parameters for evaluating leaf water status and osmoregulation ability. Terminal and persistent heat stress induces water deficit and imbalance in osmoregulation in leaves on account of acceleratory transpiration for heat emission and metabolic disturbance. Our previous study has proved that heatinduced water loss and decline in osmotic adjustment in leaves could be effectively alleviated by the exogenous application of GABA contributing to enhanced thermotolerance in creeping bentgrass (Li et al., 2016). Based on an integrated analysis of five physiological parameters (EL, Chl content, $\mathrm{PI}_{\mathrm{ABS}}$, RWC, and $\mathrm{OP}$ ), notable genetic variations were found among 41 creeping bentgrass materials, and LOFTS L-93, PROVEINDENCE, and $13 \mathrm{M}$ exhibited better heat tolerance, but PENNEAGLE, W6 6569, and W6 6570 had worse heat tolerance than other materials. Pearson correlation coefficients analysis showed that Chl content, OP, or EL had first, second, or third highest correlation coefficient with the SFVA ranking of heat tolerance among the 41 creeping bentgrass accessions, respectively. A recent study on natural variation of heat tolerance among 98 perennial ryegrass accessions also demonstrated that EL and Chl content were the top two evaluation parameters that exhibited high correlation coefficients with heat tolerance (Zhang et al., 2020). Thus, Chl and EL could be used as critical traits for a quick identification of heat tolerance among a large number of cool-season grass germplasms.

Greenhouse or growth chamber test under controlled environment conditions provides relatively stable heat stress in day and night, but high temperature under summer stress is fluctuant in nature and is accompanied by other complex factors such as changes in wind, air humidity, and solar ultraviolet radiation (Gaffen and Ross, 1998; Wang and Gaffen, 2001; Zhou et al., 2021). Therefore, crops that have stronger tolerance to fluctuant high temperature in summer are of great practical value. Eighteen creeping bentgrass materials with better heat tolerance selected from the controlled experiment in growth chambers were further tested under field conditions in the summer of 2020. The findings showed that significant variations in EL, Chl content, $\mathrm{PI}_{\mathrm{ABS}}, \mathrm{Fv} / \mathrm{Fm}$, and $\mathrm{TQ}$ were found in the 18 

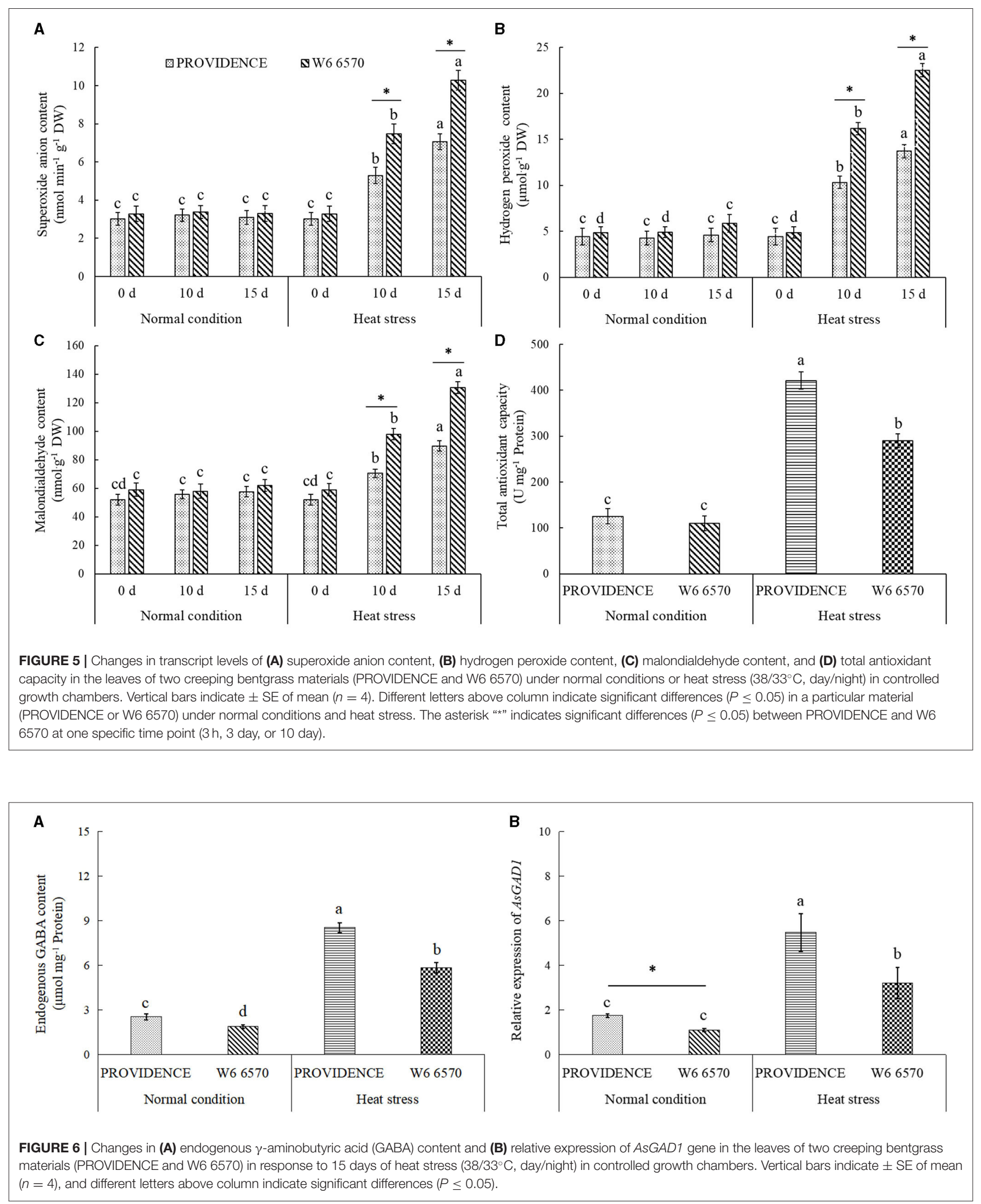


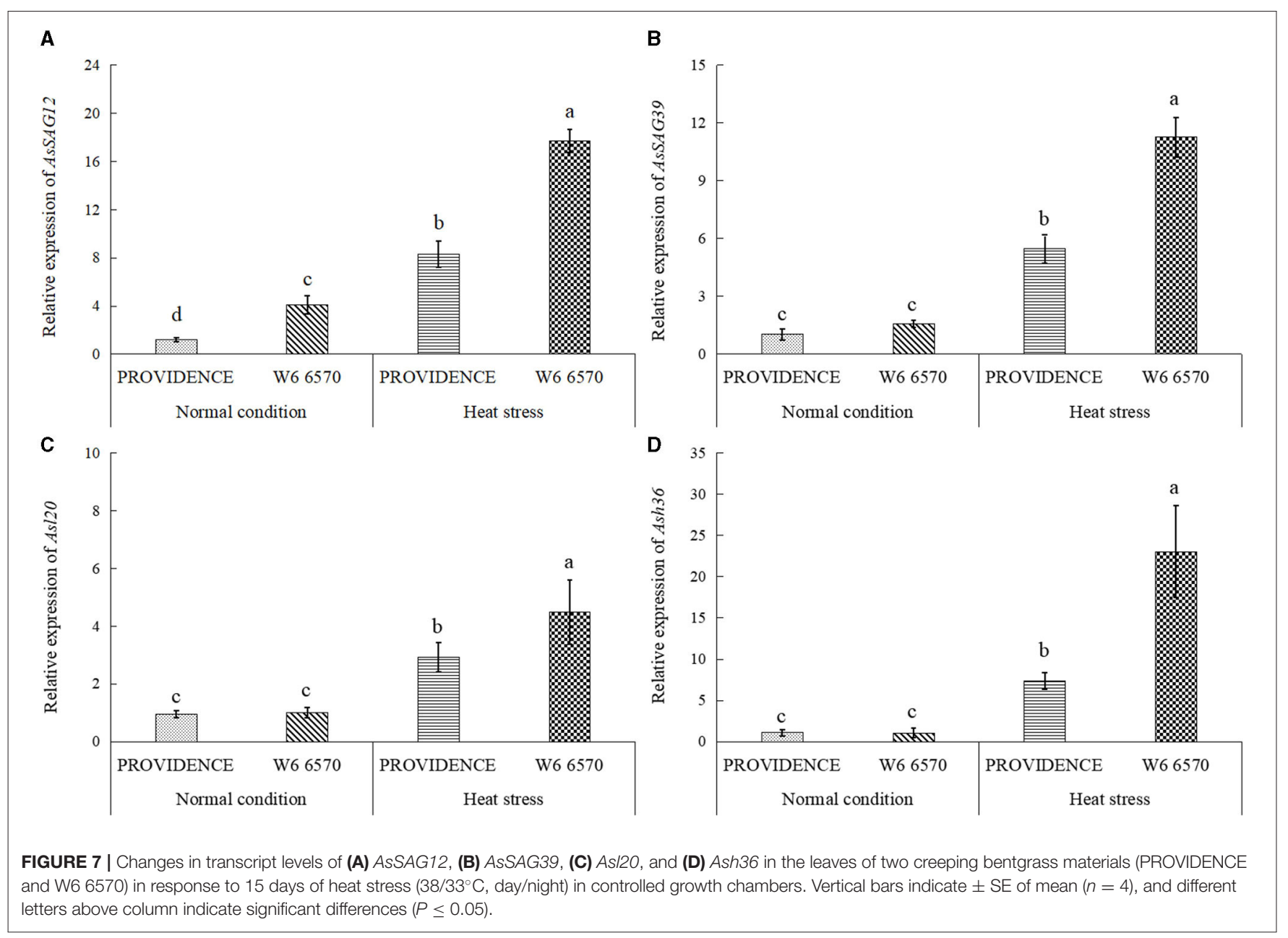

materials under high temperature stress (daily maximum average temperature above $30^{\circ} \mathrm{C}$ for 32 days) in summer, in agreement with chamber-grown plants under controlled conditions. It has been reported that $\mathrm{PI}_{\mathrm{ABS}}$ could act as an efficient breeding trait for the selection of heat-tolerant maize in field environments (Galic et al., 2019). In addition, TQ and Chl content could explain $40 \%$ genetic variations in the heat tolerance of 120 tall fescue accessions (Sun et al., 2014). In this study, 13M, PROVIDENCE, and LOFTS L-93 were identified as the most tolerant materials, and ProCup, MSCB-19, and NATIONAL had less heat tolerance than the other materials according to the SFVA using five parameters (EL, Chl content, PIABS, Fv/Fm, and TQ) in the field. Although the general raking trends between field test and the evaluation in growth chambers were similar, some differences were still not ignored. An earlier study suggested that laboratory screening test could be an accurate and rapid approach for selecting Kentucky bluegrass and perennial ryegrass differing in heat tolerance, since the results from field testing followed similar trends as the results under artificial conditions using growth chambers (Minner et al., 1983). Common bean (Phaseolus vulgaris) genotypes with superior heat tolerance could be successfully identified through conjoint estimations in the field and in the greenhouse (Porch, 2006). These findings indicate that integrative screening by laboratory and field tests could provide a more accurate evaluation of adaptation to high temperature in summer, because summer stress in the field depends on a particular location, weather, and soil condition.

A long-term period of heat stress retarded photosynthetic process and plant growth associated with the loss of Chl, which is the most important pigment for light harvest and transportation. Accompanied by accelerated leaf chlorosis under heat stress, significant declines in Pn and photochemical efficiency of PSII have been reported in creeping bentgrass and other plant species (Liu et al., 2019; Luo et al., 2020). Our current findings demonstrated that PROVIDENCE, having better heat tolerance, maintained significantly higher $\mathrm{Chl}, \mathrm{Pn}, \mathrm{Fv} / \mathrm{Fm}$, and $\mathrm{PI}_{\mathrm{ABS}}$ than the heat-susceptible W6 6570 under optimal and high temperature conditions, indicating a significant genetic variation in $\mathrm{Chl}$ and photosynthesis between them. It has been reported that the maintenance of $\mathrm{Chl}$ cycle and photosynthetic complexes contributed to delayed leaf senescence in rice (Oryza sativa) (Krishna et al., 2016). For Chl anabolism, four prophobilinogen subunits are combined together into a tertapyrrole ring by PBGD; $\mathrm{Mg}-\mathrm{CHT}$ is responsible for the insertion of $\mathrm{Mg}^{2+}$; POR catalyzes the formation of chlorophyllide (Masuda and Fujita, 2008). PPH is a key Chl-catabolic enzyme that catalyzes the removal of 
phytol chain from pheophytin (Schelbert et al., 2009). Heat stress attenuated $\mathrm{Chl}$ biosynthesis in the leaves of both PROVIDENCE and W6 6570, but PROVIDENCE showed better performance than W6 6570 through the maintenance of significantly higher expression levels of Chl-anabolic genes ( $A s C H L H, A s P B G D$, and $A s P O R$ ) and lower Chl-catabolic gene $A s P P H$ under heat stress. A previous study has confirmed that a delay in heat-induced leaf senescence could be modulated by gene expression involved in Chl biosynthesis (Luo et al., 2020). Suppression or decrease in $P P H$ expression or encoding enzyme activity played a critical role in alleviating leaf senescence induced by heat stress in coolseason grass species (Jespersen et al., 2016; Jing et al., 2019; Rossi et al., 2020). Transcript levels of senescence-associated genes (As120, Ash12, AsSAG12, and AsSAG39) also indicated that PROVIDENCE exhibited delayed senescence as compared with W6 6570 after 15 days of heat stress.

Reactive oxygen species detoxification by an antioxidant system is one of the basic mechanisms for anti-aging in plants and animals (Munné-Bosch and Alegre, 2004; Pierpaola et al., 2016). The overaccumulation of detrimental ROS in stressed plants is accompanied by oxidative damage to proteins and membrane lipids, bringing about the disruption of chloroplast structure (Farooq et al., 2019). Melatonin suppressed heat- and dark-induced leaf senescence through enhancing activities of ROS-scavenging enzymes, thereby decreasing oxidative damage to cells (Zhang et al., 2016; Jing et al., 2019). In addition, the enhancement of antioxidant defense and ROS scavenging modulated by melatonin contributed to the delay of dehydrationinduced leaf senescence in tobacco (Nicotiana tabacum) (Chen et al., 2021). Leaf senescence could be also effectively mitigated by the exogenous application of cytokinin or mannose involved in the improvement of antioxidant systems and ROS scavenging in grass species under salt or drought condition (Ma et al., 2016; Zhao et al., 2020). Persistent heat stress induced gradual increases in $\mathrm{O}_{2} \cdot-\mathrm{H}_{2} \mathrm{O}_{2}$, and MDA content, indicating heatinduced oxidative damage to PROVIDENCE and W6 6570. However, less oxidative damage and higher TAC were detected in PROVIDENCE relative to W6 6570 during heat stress. Therefore, a genetic variation in antioxidant capacity and ROS scavenging could play a vital part in stay-green trait in creeping bentgrass species.

As a non-protein amino acid, GABA is involved in nitrogen balance, energy metabolism, and metabolic shift with other metabolites (Fait et al., 2008; Lee et al., 2021). Enhanced GABA accumulation or metabolism could contribute to better adaptation to abiotic stresses, such as heat stress, in different plant species (Li et al., 2019; Tang et al., 2020; Rossi et al., 2021). The catabolism of GABA produces glutamic acid, which is an important biosynthetical precursor of Chl (Bouché and Fromm, 2004). An exogenous supply of GABA or chitosan improved endogenous GABA content, thereby alleviating salt- or droughtinduced $\mathrm{Chl}$ loss in leaves of creeping bentgrass or white clover (Li et al., 2017, 2020). Despite the role of GABA as a metabolite for nutrition, metabolic homeostasis, and osmotic adjustment, increasing evidence indicates that the GABA plays a signaling molecule involved in stress response in plants (Fromm, 2020). GABA induced a significant improvement in antioxidant enzyme activities and upregulated stress-defensive genes encoding heat shock proteins, dehydrins, aquaporins, and osmotin against heat stress damage in sunflower (Helianthus annuus) (Abdel Razik et al., 2021). Khan et al. summarized the critical role of GABA in plant senescence via the regulation of oxidative damage, cytosolic $\mathrm{pH}$, and carbon-nitrogen pool (Khan et al., 2021). A recent study also found that the suppression of $\mathrm{PPH}$ expression by GABA could significantly inhibit heat-caused Chl breakdown in creeping bentgrass (Rossi et al., 2020). In response to heat stress, endogenous GABA content and the expression of AsGAD1 involved in GABA biosynthesis significantly increased in both the PROVIDENCE and W6 6570 genotypes. More importantly, PROVIDENCE maintained a significantly higher endogenous GABA content and the expression of AsGAD1 under normal conditions and heat stress. Genetic variation in GABA could be beneficial in mitigating aging-induced leaf senescence and heatinduced detrimental effects, such as leaf chlorosis and metabolic disturbance, to achieve a stay-green phenotype. However, it still requires further investigations to uncover the role of GABA in leaf senescence based on genetic, metabolic, and molecular study.

\section{CONCLUSION}

There were significant genetic variations in physiological traits (EL, RWC, OP, Chl content, Fv/Fm, $\mathrm{PI}_{\mathrm{ABS}}$, and TQ) among 41 creeping bentgrass accessions that originated from 15 different countries. The $13 \mathrm{M}$, the PROVIDENCE, and the LOFTS L93 were the top three cultivars with better tolerance to high temperature and summer stress than other materials based on laboratory and field tests. In response to heat stress, staygreen genotype PROVIDENCE exhibited significantly higher photochemical efficiency, Pn, Tr, and WUE than W6 6570 with susceptibility to heat damage. Delayed leaf senescence associated with less Chl loss was detected in PROVIDENCE via the maintenance of significantly higher expression levels of Chl-anabolic genes ( $A s C H L H, A s P B G D$, and $A s P O R$ ) and lower expression level of Chl-catabolic gene $A s P P H$ under heat stress. Genetic attributes of better ROS-scavenging capacity and higher endogenous GABA content could play positive roles in alleviating heat-induced senescence, oxidative damage, and metabolic disturbance in PROVIDENCE. Genetic and molecular mechanisms are still required to elucidate the relationship between stay-green variation and heat tolerance in creeping bentgrass species.

\section{DATA AVAILABILITY STATEMENT}

The original contributions presented in the study are included in the article/supplementary material, further inquiries can be directed to the corresponding author/s.

\section{AUTHOR CONTRIBUTIONS}

ZL and YP: conceived and designed the research. MT: conducted the experiments. MT and ZL: evaluated the data. $\mathrm{LH}, \mathrm{ZL}$, and YP: provided different chemical reagents and experimental material. 
Article writing was completed by ZL. MT, LH, YP, YZ, and MH: reviewed and edited the manuscript. All authors contributed to the article and approved the submitted version.

\section{FUNDING}

This research was supported by China Postdoctoral Science Foundation (2021T140058) and the Sichuan Forage Innovation

\section{REFERENCES}

Abdel Razik, E.S., Alharbi, B.M., Pirzadah, T.B., Alnusairi, G.S.H., Soliman, M.H., and Hakeem, K.R. (2021). $\gamma$-Aminobutyric acid (GABA) mitigates drought and heat stress in sunflower (Helianthus annuus L.) by regulating its physiological, biochemical and molecular pathways. Physiol. Plant. 172, 505-527. doi: 10.1111/ppl.13216

Ahamed, K. U., Nahar, K., and Fujita, M. (2010). Variation in plant growth, tiller dynamics and yield components of wheat (Triticum aestivum L.) due to high temperature stress. Advan. Agric. Botanics 2, 213-224.

Amnon, D. (1949). Copper enzymes in isolated chloroplasts. Polyphenoloxidase inBeta vulgaris .Plant Physiol. 24, 1-15. doi: 10.1104/pp.24.1.1

Barrs, H., and Weatherley, P. (1962). A re-examination of the relative turgidity technique for estimating water deficits in leaves. Aust. J. Biol. Sci. 15, 413-428. doi: $10.1071 /$ BI9620413

Beard, J.B., and Batten, S.M. (2001). Turf Management for Golf Courses. 2nd Edition. New Jersey: John Wiley Press.

Blum, A. (1989). Osmotic adjustment and growth of barley genotypes under drought stress. Crop Sci. 29, 230-233. doi: $10.2135 /$ cropsci1989.0011183X002900010052x

Blum, A., and Ebercon, A. (1981). Cell membrane stability as a measure of drought and heat tolerance in wheat. Crop Sci. 21, 43-47. doi: 10.2135/cropsci1981.0011183X002100010013x

Bouché, N., and Fromm, H. (2004). GABA in plants: just a metabolite? Trends Plant Sci. 9, 110-115. doi: 10.1016/j.tplants.2004.01.006

Chen, M. (2014). Chlorophyll modification and their spectral extension in oxygenic photosynthesis. Ann. Rev. Biochem. 83, 317-340 doi: 10.1145/2582112

Chen, Z., Jia, W., Li, S., Xu, J., and Xu, Z. (2021). Enhancement of Nicotiana tabacumresistance against dehydration-induced leaf senescence via metabolite/phytohormone-gene regulatory networks modulated by melatonin. Front. Plant Sci. 12, 686062. doi: 10.3389/fpls.2021.686062

Dai, Y., Yuan, L., Zhang, S., Wang, J., Xie, S., Zhao, M., et al. (2019). Comprehensive evaluation for cold tolerance in Wucai (Brassica campestris L.) by the performance index on an Absorption Basis (PIabs). Agronomy 9, 61. doi: 10.3390/agronomy 9020061

Dhindsa, R., Plumb-Dhindsa, P., and Thorpe, T. (1981). Leaf senescence: correlated with increased levels of membrane permeability and lipid peroxidation, and decreased levels of superoxide dismutase and catalase. J. Exp. Bot. 32, 93-101. doi: $10.1093 / \mathrm{jxb} / 32.1 .93$

Doru, A. (2021). Effects of heat stress on photosystem II activity and antioxidant enzymes in two maize cultivars. Planta 253, 1-15. doi: $10.1007 /$ s00425-021-03611-6

Elstner, E.F., and Heupel, A. (1976). Inhibition of nitrite formation from hydroxylammoniumchloride: a simple assay for superoxide dismutase. Anal. Biochem. 70, 616-620. doi: 10.1016/0003-2697(76)90488-7

Fait, A., Fromm, H., Walter, D., Galili, G., and Fernie, A.R. (2008). Highway or byway: the metabolic role of the GABA shunt in plants. Trends Plant Sci. 13, 14-19. doi: 10.1016/j.tplants.2007.10.005

Farooq, M.A., Niazi, A.K., Akhtar, J., Ullah, S., and Rengel, Z. (2019). Acquiring control: the evolution of ROS-induced oxidative stress and redox signaling pathways in plant stress responses. Plant Physiol. Biochem. 141, 353-369. doi: 10.1016/j.plaphy.2019.04.039

Fromm, H. (2020). GABA Signaling in plants: Targeting the missing pieces of the puzzle. J. Exp. Bot. 71, 6238-6245. doi: 10.1093/jxb/eraa358
Team Project of the Industrial System Construction of Modern Agriculture of China (sccxtd-2020-16).

\section{SUPPLEMENTARY MATERIAL}

The Supplementary Material for this article can be found online at: https://www.frontiersin.org/articles/10.3389/fpls.2021. 750728/full\#supplementary-material

Gaffen, D.J., and Ross, R.J. (1998). Increased summertime heat stress in the US. Nature 396, 529-530. doi: 10.1038/25030

Galic, V., Franic, M., Jambrovic, A., Ledencan, T., Brkic, A., Zdunic, Z., et al. (2019). Genetic correlations between photosynthetic and yield performance in maize are different under two heat scenarios during flowering. Front. Plant Sci. 10, 566. doi: 10.3389/fpls.2019.00566

Hoagland, D.R., and Arnon, D.I. (1950). The waterculture method for growing plants without soil. Calif. Agric. Exp. Stn.347, 357-359.

Huang, B., Dacosta, M., and Jiang, Y. (2014). Research advances in mechanisms of turfgrass tolerance to abiotic stresses: from physiology to molecular biology. Crit. Rev. Plant Sci.33, 141-189. doi: 10.1080/07352689.2014.870411

Huang, B., and Gao, H. (2000). Growth and carbohydrate metabolism of creeping bentgrass cultivars in response to increasing temperatures. CropSci. 40, 1115-1120. doi: 10.2135/cropsci2000.4041115x

Imada, T., Razmjoo, K., Hirano, J., Kaneko, S., and Ishii, R. (1993). Response of perennial ryegrass (Lolium perenne L.) cultivars to heat stress. Japanese J. Grassland Sci.39, 225-235.

Jespersen, D.,Zhang, J., and Huang, B. (2016). Chlorophyll loss associated with heat-induced senescence in bentgrass. Plant Sci. 249, 1-12. doi: 10.1016/j.plantsci.2016.04.016

Jing, Z.A., Jing, X.A., Ql, A., Gy, A., Bx, A., and Bh, B. (2019). Transcriptional regulation of chlorophyll-catabolic genes associated with exogenous chemical effects and genotypic variations in heat-induced leaf senescence for perennial ryegrass. Environ. Exp. Bot. 167, 103858. doi: 10.1016/j.envexpbot.2019.103858

Kenneth, J.L., and Thomas, D.S. (2002). Analysis of relative gene expression data using real-time quantitative PCR and the $2^{-\Delta \Delta C T}$ method. Methods 25, 402-408. doi: 10.1006/meth.2001.1262

Khan, M., Jalil, S.U., Chopra, P., Chhillar, H., and Ansari, M.I. (2021). Role of GABA in plant growth, development and senescence. Plant Gene. 26, 100283. doi: 10.1016/j.plgene.2021.100283

Krishna, T.S., Madhusmita, P., Saivishnupriya, K., Nirosha, P., Sarla, N., and Rajeshwari, R. (2016). Cytokinin delays dark-induced senescence in rice by maintaining the chlorophyll cycle and photosynthetic complexes. J. Exp. Bot. 67, 1839-1851. doi: 10.1093/jxb/erv575

Lee, J., Kim, S., Kim, S., and Shim, I.S. (2021). Production of $\gamma$-aminobutyric acid and its supplementary role in the TCA cycle in rice (Oryza sativa L.) seedlings. J. Plant Growth Regul. 40, 78-90. doi: 10.1007/s00344-020-10066-8

Li, L., Dou, N., Zhang, H., and Wu, C. (2021). The versatile GABA in plants. Plant Signal. Behav. 16, 1862565. doi: 10.1080/15592324.2020.1862565

Li, Z., Cheng, B., Zeng, W., Zhang, X., and Peng, Y. (2020). Proteomic and metabolomic profilings reveal crucial functions of $\gamma$-aminobutyric acid in regulating Ionic, water, and metabolic homeostasis in creeping bentgrass under salt stress. J. Proteome Res. 19, 769-780. doi: 10.1021/acs.jproteome.9b00627

Li, Z., Yong, B., Cheng, B., Wu, X., Zhang, Y., Zhang, X., et al. (2019). Nitric oxide, $\gamma$-aminobutyric acid, and mannose pretreatment influence metabolic profiles in white clover under water stress. J. Integr. Plant Biol. 61, 1255-1273. doi: $10.1111 /$ jipb. 12770

Li, Z., Yu, J., Peng, Y., and Huang, B. (2016). Metabolic pathways regulated by $\gamma$ aminobutyric acid (GABA) contributing to heat tolerance in creeping bentgrass (Agrostis stolonifera). Sci. Rep. 6, 30338. doi: 10.1038/srep30338

Li, Z., Zhang, Y., Zhang, X., Merewitz, E., Peng, Y., Ma, X., et al. (2017). Metabolic pathways regulated by chitosan contributing to drought resistance in white clover. J. Proteome Res. 16, 3039-3052. doi: 10.1021/acs.jproteome.7b0 0334 
Lipiec, J., Doussan, C., Nosalewicz, A., and Kondracka, K. (2013). Effect of drought and heat stresses on plant growth and yield: a review. Int. Agrophys. 27, 463-477. doi: 10.2478/intag-2013-0017

Liu, T., Liu, Z., Li, Z., Peng, Y., He, L., Zhang, X., et al. (2019). Regulation of heat shock factor pathways by $\gamma$-aminobutyric acid (GABA) associated with thermotolerance of creeping bentgrass. Int. J. Mol. Sci. 20, 4713. doi: 10.3390/ijms20194713

Luo, L., Li, Z., Tang, M.Y., Cheng, B.Z., Zeng, W.H., Peng, Y., et al. (2020). Metabolic regulation of polyamines and $\gamma$-aminobutyric acid in relation to spermidine-induced heat tolerance in white clover. Plant Biol. 22, 794-804. doi: $10.1111 /$ plb.13139

Ma, X., Zhang, J., and Huang, B. (2016). Cytokinin-mitigation of saltinduced leaf senescence in perennial ryegrass involving the activation of antioxidant systems and ionic balance. Environ. Exp. Bot. 125, 1-11. doi: 10.1016/j.envexpbot.2016.01.002

Malhotra, S.K. (2017). Horticultural crops and climate change: a review. Indian. J. Agr. Sci. 87, 12-22.

Masuda, T., and Fujita, Y. (2008). Regulation and evolution of chlorophyll metabolism. Photochem. Photobiol. Sci. 7, 1131-1149. doi: 10.1039/b807210h

Minner, D.D., Dernoeden, P.H., Wehner, D.J., and Mcintosh, M.S. (1983). Heat tolerance screening of field-grown cultivars of Kentucky bluegrass and perennial ryegrass. Agron. J. 75, 772-775. doi: 10.2134/agronj1983.00021962007500050012x

Munné-Bosch, S., and Alegre, L. (2004). Die and let live: Leaf senescence contributes to plant survival under drought stress. Funct. Plant Biol. 31, 8808-8818. doi: 10.1071/FP03236

Parent, C., Capelli, N., and Dat, J. (2008). Reactive oxygen species, stress and cell death in plants. C R Biol. 331, 255-261. doi: 10.1016/j.crvi.2008.02.001

Pierpaola, D., Tijana, M., Andrea, C., Angela, L., and Domenico, D. (2016). ROS, cell senescence, and novel molecular mechanisms in aging and age-related diseases. Oxid. Med. Cell. Longev. 2016, 3565127. doi: 10.1155/2016/3565127

Porch, T.G. (2006). Application of stress indices for heat tolerance screening of common bean. J. Agron. Crop Sci. 192, 390-394. doi: 10.1111/j.1439-037X.2006.00229.x

Rehman, S.U., Bilal, M., Rana, R.M., Tahir, M.N., Shah, M., Ayalew, H., et al. (2016). Cell membrane stability and chlorophyll content variation in wheat (Triticumaestivum) genotypes under conditions of heat and drought. Crop Pasture Sci. 67, 712-718. doi: 10.1071/CP15385

Rossi, S., Burgess, P., Jespersen, D., and Huang, B. (2017). Heat-induced leaf senescence associated with chlorophyll metabolism in bentgrass lines differing in heat tolerance. Crop Sci. 57, 169-178. doi: 10.2135/cropsci2016.06. 0542

Rossi, S., Chapman, C., and Huang, B. (2020). Suppression of heat-induced leaf senescence by $\gamma$-aminobutyric acid, proline, and ammonium nitrate through regulation of chlorophyll degradation in creeping bentgrass. Environ. Exp. Bot. 177, 104116. doi: 10.1016/j.envexpbot.2020.104116

Rossi, S., Chapman, C., Yuan, B., and Huang, B. (2021). Improved heat tolerance in creeping bentgrass by $\gamma$-aminobutyric acid, proline, and inorganic nitrogen associated with differential regulation of amino acid metabolism. Plant Growth Regul. 93, 231-242. doi: 10.1007/s10725-020-00681-6

Schelbert, S., Aubry, S., Burla, B., Agne, B., Kessler, F., Krupinska, K., et al. (2009). Pheophytin pheophorbide hydrolase (pheophytinase) is involved in chlorophyll breakdown during leaf senescence in Arabidopsis. Plant Cell 21, 767-785. doi: 10.1105/tpc.108.064089

Sharma, P., Sareen, S., and Saini, M. (2016). Assessing genetic variation for heat stress tolerance in Indian bread wheat genotypes using morphophysiological traits and molecular markers. Plant Genet. Resour. 15, 539-47. doi: $10.1017 /$ S1479262116000241

Sun, Q., Miao, C., Hanel, M., Borthwick, A., and Li, H. (2019). Global heat stress on health, wildfires, and agricultural crops under different levels of climate warming. Enviro. Int. 128, 125-136. doi: 10.1016/j.envint.2019. 04.025

Sun, X., Hu, L., Xie, Y., and Fu, J. (2014). Evaluation of genotypic variation in heat tolerance of tall fescue by functional traits. Euphytica 199, 247-260. doi: 10.1007/s10681-014-1122-4

Tang, M., Li, Z., Luo, L., Cheng, B., and Peng, Y. (2020). Nitric oxide signal, nitrogen metabolism, and water balance affected by $\gamma$-aminobutyric acid (GABA) in relation to enhanced tolerance to water stress in creeping bentgrass. Int. J. Mol. Sci. 21, 7460. doi: 10.3390/ijms21207460

Tewari, K. (1998). Temperature-stress-induced impairment of chlorophyll biosynthetic reactions in cucumber and wheat. Plant Physiol. 117, 851-858. doi: 10.1104/pp.117.3.851

Thistlethwaite, R.J., Tan, D.K.Y, Buckley, T.N., and Trethowan, R.M. (2015) Identification of genetic variation in heat stress and mechanisms of tolerance in wheat. Procedia Environ. Sci. 29, 30. doi: 10.1016/j.proenv.2015.07.139

Van Vuuren, D.P., Meinshausen, M., Plattner, G.K., Joos, F., Strassman, K.M., Smith, S.J., et al. (2009). Temperature increase of 21 st century mitigation scenarios. Proc. Nat. Acad. Sci. USA 105, 15258-15262. doi: 10.1073/pnas.0711129105

Velikova, V., Yordanov, I., and Edreva, A. (2000). Oxidative stress and some antioxidant systems in acid rain-treated bean plants: protective role of exogenous polyamines. Plant Sci. 151, 59-66. doi: 10.1016/S0168-9452(99)00197-1

Wang, J.X.L., and Gaffen, D.J. (2001). Trends in extremes of surface humidity, temperature, and summertime heat stress in China. Adv. Atmos. Sci. 18, 742-751. doi: 10.1007/BF03403499

Zhang, J., Li, H., Jiang, Y., Li, H., and Huang, B. (2020). Natural variation of physiological traits, molecular markers, and chlorophyll catabolic genes associated with heat tolerance in perennial ryegrass accessions. BMC Plant Biol. 20, 520. doi: 10.1186/s12870-020-02695-8

Zhang, J., Li, H., Xu, B., Li, J., and Huang, B. (2016). Exogenous melatonin suppresses dark-induced leaf senescence by activating the superoxide dismutase-catalase antioxidant pathway and down-regulating chlorophyll degradation in excised leaves of perennial ryegrass (Loliumperenne L.). Front. Plant Sci. 7, 1500. doi: 10.3389/fpls.2016.01500

Zhao, S. Y., Zeng, W. H., Li, Z., and Peng, Y. (2020) Mannose regulates water balance, leaf senescence, and genes related to stress tolerance in white clover under osmotic stress. Biol. Plant. 64, 406-416. doi: 10.32615/bp.2020.017

Zhou, H., Huang, X., Zhou, W., Zhang, Y., and Liu, Y. (2021). Spatial correlation length of summer extreme heat stress over eastern China. Int. J. Climatol. 41, 3121-3138. doi: 10.1002/joc.7009

Conflict of Interest: The authors declare that the research was conducted in the absence of any commercial or financial relationships that could be construed as a potential conflict of interest.

Publisher's Note: All claims expressed in this article are solely those of the authors and do not necessarily represent those of their affiliated organizations, or those of the publisher, the editors and the reviewers. Any product that may be evaluated in this article, or claim that may be made by its manufacturer, is not guaranteed or endorsed by the publisher.

Copyright (c) $2021 \mathrm{Li}$, Tang, Hassan, Zhang, Han and Peng. This is an open-access article distributed under the terms of the Creative Commons Attribution License (CC $B Y)$. The use, distribution or reproduction in other forums is permitted, provided the original author(s) and the copyright owner(s) are credited and that the original publication in this journal is cited, in accordance with accepted academic practice. No use, distribution or reproduction is permitted which does not comply with these terms. 